Richard J. Courtheoux

is President and Founder of Marketing Analysis

Applications, a management consulting firm. He has worked in direct marketing since 1978 and was formerly Senior Vice President of Database and

Consulting Services for

Experian, President of Precision Marketing and a consultant at Kestnbaum and Company.

Keywords: statistical modelling, multichannel marketing, CRM, database marketing,customer predictive modelling, contact management
Richard J. Courtheoux Marketing Analysis Applications 566 Woodlawn Avenue Glencoe

IL 60022

USA

Tel: +1 8472420318

Fax: +1 8476310865

E-mail: rcourtheoux@

maa-online.com

\section{Modelling multichannel response behaviour}

\author{
Richard J. Courtheoux \\ Received (in revised form): 30 May 2003
}

\begin{abstract}
For most organisations, the marketing realities of the 21 st century include both stimulating demand through multiple media and capturing demand through multiple channels. To build models that provide a solid basis for customer segmentation and marketing contact decisions, marketers must be able to isolate and predict the incremental impact of each contact. This paper discusses recommended procedures for diagnosing the structure of the marketing situation with respect to multiple interacting channels and the subsequent appropriate choices of models that should be created. It also explores issues related to the accurate creation of behavioural (dependent) and predictive (independent) variables as a key modelling success factor in a multichannel marketing environment.
\end{abstract}

\section{Introduction}

Internet mania has expired, but out of the spasms and turbulence has emerged an economically sustainable marketing paradigm relying on multiple channels of both stimulation and response. Survivor companies regularly stimulate customer demand through targeted communications in several media, and they must be ready to process orders through several channels. Although multichannel marketing programmes certainly existed before the internet became commercially important, their scale and complexity has jumped in recent years.

As the expenditures on multichannel, targeted marketing are now larger, it is commensurately more important for behavioural modelling procedures to reflect this reality. The predictive modelling of behaviours such as response rates is the foundation for segmentation and decision making with respect to marketing customer contacts. In most companies, however, current modelling and marketing management decisions are based on a simpler framework. Leading database marketing books focus on relatively straightforward modelling situations where predictive scores support segmenting customers into groups with very different expected levels of performance. ${ }^{1,2}$ Certain assumptions are made.

- All demand results from a targeted communication. With many traditional direct mail programmes (eg catalogues) this is not a bad assumption, since virtually no demand will come in without marketing stimulation. The assumption has never been good for retail traffic-building campaigns and it is definitely a poor assumption for internet demand. 


\section{Undervaluation and overvaluation errors}

\section{Predict incremental changes in behaviour}

- Order keycode capture and name match-back techniques can associate demand with the right person and marketing campaign. Keycode capture rates in some channels (eg internet and retail) tend to be very low and name match-backs identify only which demand might have been stimulated by a particular targeted communication.

Financially optimal marketing decisions need a modelled estimate for each individual of the total value of behaviours that might be stimulated by a potential marketing expenditure. In these situations there are lurking miscalculations that can either undervalue or overvalue the marketing contact (Figure 1).

- Undervaluation occurs when demand from one or more channels is not considered. A simple, yet widespread, example of this type of error occurs every time a catalogue circulation decision is based only on expected offline demand.

- Overvaluation occurs when all identified demand from a name is attributed to a targeted marketing effort. For example, much of the demand at an internet site will materialise whether or not an individual gets a targeted marketing contact.

For predictive models to play their intended role in driving targeted marketing selections, they must be highly accurate in predicting incremental changes in all relevant behaviours. Subsequent sections of this paper will identify modelling methodology issues and options. In order to make the discussion relevant and realistic, the focus will be on a business situation where targeted (offline) direct mail is used in combination with the (online) internet. Wider generalisations to other media and channels will be discussed in a concluding section. For better

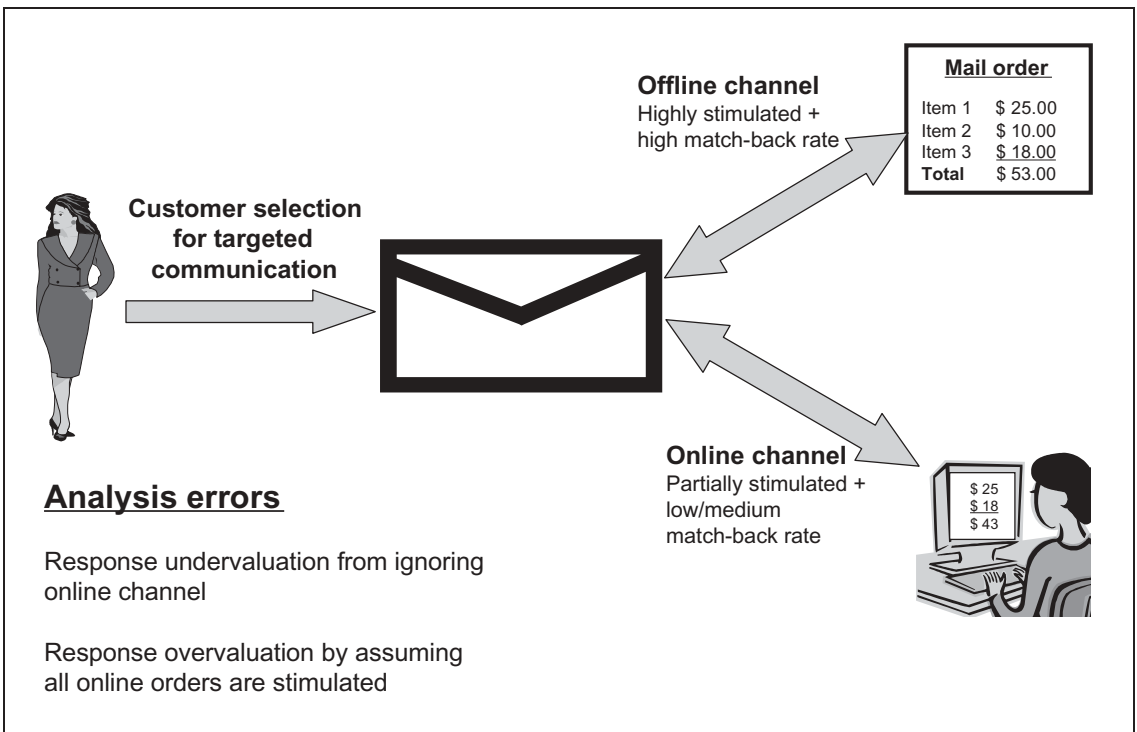

Figure 1: Multichannel response behaviour 
or worse, marketing realities are now more complex, so the commercially most effective modelling solutions are also likely to be more complex than those of the past.

\section{Implications for modelling}

Building predictive models for targeted multichannel direct marketing demands thought in the usual three dimensions.

- Problem formulation and solution design. The modeller has to make decisions about which particular models should be built and the associated required datasets.

- Development of variables, both dependent and independent. Customer response in different purchasing channels will almost certainly have different economic characteristics, and each channel's response level is likely to be best predicted by a channel-specific model. This implies developing appropriate dependent variables to reflect each channel's activity. Since customers will usually have some channel preference tendencies, independent variables should reflect prior activity by channel.

- Choice and application of analytical technique. There is no particular reason to believe that the choice of multiple regression, neural networks, chi-squared automatic interaction detector (CHAID) or any other modelling technique should be affected by the multichannel problem domain. Since the relative merits of these techniques have been discussed in many other sources, they will not be considered further here.

This paper will largely focus on the options and considerations related to building the most effective models. A practitioner should keep in mind that each additional refinement does add cost, complexity and potential for error. But, other than in very small businesses, multichannel marketers should improve their marketing efficiency by implementing many of the ideas recommended below.

\section{Simple modelling situations}

\section{Problem formulation and solution design}

Before rushing ahead, the modeller and the marketer should consider whether a 'simple and lucky' reality exists. For purposes of this discussion, a simple and lucky situation is one where the following two conditions are true.

- Customer propensity to purchase in any one channel is highly correlated with propensity to purchase in all other channels. If, however, certain types of customers display a clear channel preference or if customers just display consistency in their choice of channel, then this condition is false.

- The incremental effect of a targeted communication is proportional to the propensity to purchase. If, among customers with the same propensity to buy, some are more easily stimulated to buy, then this condition is false. 


\section{Check stability of internet usage among segments}

\section{Channel-preference- only situations}

When both conditions are true the situation is simple and the modeller gets lucky because the single-channel modelling solution can be deployed to support the multichannel environment. The marketer needs to do some financial calculations to incorporate accurately the costs associated with each channel and the anticipated channel distribution of sales. Since most multichannel situations are not simple and lucky, this solution will usually be financially sub-optimal. Nevertheless, it may be an adequate starting point and, in any event, it can serve as the base case against which the financial superiority of other solutions can be measured.

To test whether a simple and lucky situation exists a company should use the marketing database to prepare the type of summary illustrated in Table 1. Names are scored using a single-channel model, sorted based on their scores and grouped into deciles. For each decile the average customer purchase productivity in each channel is calculated. If the percentage of sales by channel varies widely by decile, then the first condition mentioned above is false. On the other hand, if the percentage of sales is largely consistent by decile, this condition could still be false at an individual level, but a single-purchase model might still be a viable solution as discussed below for channel-preference-only situations.

Assessing the second condition requires controlled test data for matched panels of contacted and non-contacted customers. Test results should be summarised as illustrated in Table 2. If both the 'Demand' and 'Incremental demand' columns show the desired pattern of higher values in the top deciles and lower values in the bottom deciles, then the second condition holds. It is still possible that superior results might be obtained by modelling incremental demand, but the commercial desirability of going in that direction depends on comparing the increase in modelling expense with the incremental 'Incremental demand' achieved by a superior model.

Many situations can be characterised as 'channel preference only' in that there are basic drivers of a customer's overall likelihood of purchase that are very similar across channels, but for individual customers there are predictable or consistent preferences for one channel over the others. In these situations a single demand model may be combined with a

Table 1: Per customer demand by channel

\begin{tabular}{|cccc|}
\hline Decile & $\begin{array}{c}\text { Offline } \begin{array}{c}\text { demand/customer } \\
\mathbf{( \$ )}\end{array} \\
\text { Internet }\end{array}$ & $\begin{array}{c}\text { demand/customer } \\
\mathbf{( \$ )}\end{array}$ & $\begin{array}{c}\text { Internet demand } \\
\mathbf{\%}^{*}\end{array}$ \\
\hline 1 & 7.92 & 5.11 & 39.2 \\
2 & 3.32 & 2.55 & 43.4 \\
3 & 2.28 & 1.62 & 41.5 \\
4 & 1.61 & 1.08 & 40.2 \\
5 & 1.23 & 0.82 & 39.9 \\
6 & 0.99 & 0.68 & 40.6 \\
7 & 0.79 & 0.60 & 43.0 \\
8 & 0.72 & 0.55 & 43.4 \\
9 & 0.60 & 0.49 & 45.1 \\
10 & 0.58 & 0.49 & 45.8 \\
\hline
\end{tabular}

* Internet demand \% = Internet demand/(offline demand + internet demand) 
Table 2: Per customer contact incremental effects

\begin{tabular}{|c|c|c|c|c|c|c|}
\hline \multirow[t]{2}{*}{ Decile } & \multicolumn{3}{|c|}{ Offline } & \multicolumn{3}{|c|}{ Internet } \\
\hline & $\begin{array}{c}\text { Contact } \\
(\$)\end{array}$ & $\begin{array}{c}\text { No } \\
\text { contact } \\
(\$)\end{array}$ & $\begin{array}{l}\text { Incremental } \\
\text { demand } \\
(\$)\end{array}$ & $\begin{array}{c}\text { Contact } \\
(\$)\end{array}$ & $\begin{array}{c}\text { No } \\
\text { contact } \\
(\$)\end{array}$ & $\begin{array}{l}\text { Incrementa } \\
\text { demand } \\
(\$)\end{array}$ \\
\hline 1 & 7.92 & 0.23 & 7.69 & 5.11 & 2.99 & 2.12 \\
\hline 2 & 3.32 & 0.10 & 3.22 & 2.55 & 1.52 & 1.03 \\
\hline 3 & 2.28 & 0.10 & 2.18 & 1.62 & 0.97 & 0.65 \\
\hline 4 & 1.61 & 0.07 & 1.53 & 1.08 & 0.65 & 0.44 \\
\hline 5 & 1.23 & 0.05 & 1.18 & 0.82 & 0.48 & 0.34 \\
\hline 6 & 0.99 & 0.05 & 0.94 & 0.68 & 0.39 & 0.29 \\
\hline 7 & 0.79 & 0.04 & 0.75 & 0.60 & 0.36 & 0.24 \\
\hline 8 & 0.72 & 0.03 & 0.69 & 0.55 & 0.33 & 0.22 \\
\hline 9 & 0.60 & 0.03 & 0.57 & 0.49 & 0.30 & 0.19 \\
\hline 10 & 0.58 & 0.05 & 0.53 & 0.49 & 0.30 & 0.19 \\
\hline
\end{tabular}

\section{Many situations exhibit consistent channel preference}

simple channel allocation procedure to give marketing management an efficient selection mechanism.

A way to approach the 'channel-preference-only' situation would be to look at prior purchasing behaviour by channel. Grouping customers based on their prior percentage of demand by channel often reveals clear patterns of consistency in channel usage. The 'Contact' columns from Table 2 can be broken down as illustrated in Tables 3 and 4. Those tables clearly show a realistic level of consistency in channel preference.

Predicting accurately the demand by channel is highly important if the operational costs of fulfilling demand differ significantly by channel. It may also be important if fundamental changes are being made to a channel (eg the website is being upgraded or the catalogue page count will change).

The recommendations described above for simple and lucky and channel-preference-only situations are, admittedly, shortcuts. Besides the considerations of the two conditions mentioned above, they are often likely to be good practical procedures when the following apply.

Table 3: Offline per customer sales by prior channel usage

\begin{tabular}{|ccccccc|}
\hline Decile & \multicolumn{5}{c|}{ Prior purchasing percentage by channel } \\
\cline { 2 - 7 } & $\begin{array}{c}\text { Only offline } \\
\mathbf{( \$ )}\end{array}$ & $\begin{array}{c}\text { Internet 1-24\% } \\
\mathbf{( \$ )}\end{array}$ & $\begin{array}{c}\text { Internet 25-49\% } \\
\mathbf{( \$ )}\end{array}$ & $\begin{array}{c}\text { Internet 50-74\% } \\
\mathbf{( \$ )}\end{array}$ & $\begin{array}{c}\text { Internet 75-99\% } \\
\mathbf{( \$ )}\end{array}$ & $\begin{array}{c}\text { Only internet } \\
\mathbf{( \$ )}\end{array}$ \\
\hline 1 & 7.32 & 4.81 & 3.11 & 2.09 & 0.90 \\
2 & 9.61 & 2.94 & 2.39 & 1.80 & 1.36 & 0.88 \\
3 & 3.98 & 1.70 & 2.05 & 1.06 & 0.68 \\
4 & 2.63 & 1.60 & 1.33 & 0.67 & 0.92 & 0.56 \\
5 & 1.80 & 1.25 & 1.09 & 0.91 & 0.68 & 0.55 \\
6 & 1.33 & 1.04 & 0.91 & 0.72 & 0.65 & 0.44 \\
7 & 1.07 & 0.90 & 0.82 & 0.73 & 0.62 & 0.41 \\
8 & 0.83 & 0.83 & 0.74 & 0.66 & 0.55 & 0.38 \\
9 & 0.76 & 0.62 & 0.68 & 0.59 & 0.57 & 0.36 \\
10 & 0.61 & 0.80 & 0.67 & 0.58 & 0.55 & 0.35 \\
\hline
\end{tabular}


Table 4: Internet per customer sales by prior channel usage

\begin{tabular}{|ccccccc|}
\hline Decile & \multicolumn{5}{c|}{ Prior purchasing percentage by channel } \\
\cline { 2 - 7 } & $\begin{array}{c}\text { Only offline } \\
\mathbf{( \$ )}\end{array}$ & $\begin{array}{c}\text { Internet 1-24\% } \\
\mathbf{( \$ )}\end{array}$ & $\begin{array}{c}\text { Internet 25-49\% } \\
\mathbf{( \$ )}\end{array}$ & $\begin{array}{c}\text { Internet 50-74\% } \\
\mathbf{( \$ )}\end{array}$ & $\begin{array}{c}\text { Internet 75-99\% } \\
\mathbf{( \$ )}\end{array}$ & $\begin{array}{c}\text { Only internet } \\
\mathbf{( \$ )}\end{array}$ \\
\hline 1 & 1.05 & 6.69 & 11.88 & 16.14 & 19.76 & 21.96 \\
2 & 0.68 & 3.24 & 5.26 & 7.05 & 8.93 & 10.97 \\
3 & 0.51 & 2.17 & 3.38 & 4.20 & 4.82 & 6.87 \\
4 & 0.40 & 1.69 & 2.39 & 2.93 & 3.40 & 4.00 \\
5 & 0.32 & 1.41 & 1.91 & 2.40 & 2.68 & 2.96 \\
6 & 0.27 & 1.30 & 1.55 & 1.81 & 2.01 & 2.47 \\
7 & 0.23 & 1.13 & 1.39 & 1.67 & 1.91 & 2.00 \\
8 & 0.22 & 1.07 & 1.31 & 1.57 & 1.78 & 1.85 \\
9 & 0.18 & 0.96 & 1.12 & 1.33 & 1.48 & 1.58 \\
10 & 0.18 & 0.92 & 1.07 & 1.27 & 1.43 & 1.54 \\
\hline
\end{tabular}

\section{Practical considerations}

\section{Complete modelling options}

- The scale of a business, or at least its minor channel(s), is small and the economic gain from more predictive accuracy is likely to be small.

- The available historical data are just not sufficient to support more detailed modelling. This will commonly be the case if no disciplined tests have been executed to measure incremental demand. It will also be true for businesses where one channel is new and has not reached a degree of stability in its purchasing patterns.

- Time to implement is critical and more elaborate modelling efforts will take too long.

For many businesses the shortcuts will be a good way to start addressing multichannel modelling challenges.

The most correct and accurate modelling methodology, ignoring financial and operational issues, is to build four separate models: two for each channel. Each customer can then be scored on all four models, response predictions with and without contact compared for each channel and incremental marketing contact effects estimated; this process is discussed by Hansotia and Rukstales. ${ }^{3}$ When a channel has virtually no

\begin{tabular}{|c|c|c|}
\hline \multirow{1}{*}{ Contact } & \multicolumn{1}{c|}{ Offline } & Online \\
\cline { 2 - 3 } No contact & $\begin{array}{c}\text { Traditional } \\
\text { stimulus-response }\end{array}$ & $\begin{array}{c}\text { Contact panel } \\
\text { based }\end{array}$ \\
\cline { 2 - 3 } & $\begin{array}{c}\text { Usually } \\
\text { not needed }\end{array}$ & $\begin{array}{c}\text { No contact panel } \\
\text { based }\end{array}$ \\
\cline { 2 - 2 } & \multicolumn{2}{|c|}{} \\
\hline
\end{tabular}

Figure 2: Multichannel models 
Comparing predictions

\section{Sample size considerations}

demand unless there is a marketing contact (eg the offline channel in Table 2) it is probably better not to create a no-contact model since such a model is likely to be statistically unreliable due to the small number of buyers. Moreover, the patterns of ordering picked up by the model might be very transient ones that will not repeat in the future.

It is tempting to think that this modelling exercise will simply result in a more accurate version of Table 2. But Table 2 is built from using one model to classify each customer into exactly one row (decile) and then recording performance for that customer in the appropriate row. As soon as multiple models are in use any customer can be classified to a different decile for each model. It then makes no particular sense to focus on a row and calculate incremental effects by comparing contact and no-contact performances. In this multiple model environment the calculation of incremental effects must be done at the customer level. After that is calculated for all customers it is possible to classify customers into deciles based on predicted incremental effect.

At the core of this process is the comparison of predictions from two models, a process which puts some pressure on the modelling effort. Any model generated from data has a sampling distribution variance associated with its parameters and its predictions. Malthouse ${ }^{4}$ gives an excellent description of the extent to which models may vary depending on their data sample. A linear combination of model predictions, such as the subtraction being carried out in this situation, has a sampling distribution that reflects the sampling distribution of each model individually and their covariance. In the simplest of situations, where the sampling distributions have zero covariance and equal variances, the variance of their difference will be twice that of each model's taken alone. Direct response models built from datasets with very low percentages of responders often have significant sampling distribution variances, in which case the subtraction of model predictions will aggravate the problem. As a very rough rule of thumb, since the simplest case variance of the difference is double that of the models individually, and since sampling variances are often roughly proportional to the inverse of the sample quantity, then one might aim for each model being built on a sample that is at least double the minimum quantity which would otherwise be used.

The operational and economic implications of this observation may not be trivial. Suppose that a simple and lucky situation requires a 50,000 contact sample to get 500 responses from which to build a model of the desired reliability. To build a difference estimate of the same reliability from contact and no-contact models one would be looking for two modelling samples of 100,000 each. The contact costs to generate the model sample are now higher; the revenue lost by having a large nocontact sample may also be an important consideration.

Sometimes modellers in commercial environments get pushed to build contact and no-contact pairs of models from samples that are not matched. That can produce all sorts of model biases which are hard to anticipate or describe and which make calculated differences between their predictions very problematic. This path should usually be resisted. 


\section{Isolate purchases to model}

\section{Maximise customer identification}

\section{Developing dependent variables}

It should be apparent to any modeller that the accuracy of the dependent variable is fundamental to building an accurate predictive model. The commercial reality is that there is typically a great deal of imperfection in the process of tracking purchases to a customer and a particular marketing communication. Near perfection tends to exist only for purchases where the customer supplies both a customer identifier and a keycode for the marketing communication.

A necessary first step is to have clear rules about which purchases will be considered for model building. This mostly involves defining a time period to examine that corresponds to when the marketing contact would be having an impact. The start of the time period is usually dictated by when the contact would have reached the customer. The end of the time period should be set to cover a preponderance of the response; however, extending the time period too far runs a risk of picking up unrelated activity and diluting the model's focus. It is also appropriate to screen purchases to make sure that they are related to the products addressed by the marketing communication.

Maximising the customer identification rate should involve both of the following approaches.

\section{Automatic identification}

These are technologies that carry the customer's identification along automatically. Examples include:

- telephone automatic number identification (ANI) that is transmitted to a telephone order-taking system

— internet cookies that identify the system that is communicating with a website

— printed order forms with an inkjet printed identifier or actual name and address.

The concern with using these techniques is that there may be 'over-kill' where an order is incorrectly matched to a name. Wherever possible there should be some mechanism for confirming that the customer identification has been done correctly. For example, on the phone or the internet an interaction may be scripted which asks the customer to confirm their identification, or the identification may be confirmed by a match-back.

\section{Name and address match-back}

These take the name and address collected with the purchase and match it to a list of names. In most cases it will be the list of contacted names, but it could also be a matched panel of no-contact names. There are both mature name and address matching software and newer database customer data integration technologies available for this type of process. Modellers are often not aware that the name and address match-back technologies can be run in different ways (eg with different parameter settings) that produce different results. 


\section{Modellers should analyse variable creation procedures}

- Consumer matches can be done by household, person or address. An address-level match will give the largest number of matches, but many may be 'over-kill'. Business matches can be done at the company, site, job title, individual or address level.

- Settings often control the exactness or tightness required to recognise two forms of a name and address as matching. Looser settings will tend to match a higher percentage of purchases to any base list of names. When developing modelling data one usually wants fairly loose matching settings so that the maximum number of purchases will be matched. There should be some inspection of the matches to make sure that the setting are not giving 'over-kill'.

- Specific rules can be specified in many systems. Not only will the choice of rules influence the 'over-kill' rate, but it may also create specific biases in which orders are matched back. Subsequent modelling may in effect model the match-back rules almost as much as the overall buying behaviour.

To a large extent these customer identification issues have existed for many years. The expansion of commercial internet and multichannel marketing has made the issue more critical because the traditional identity capture mechanisms have a much lower yield, making biases more likely and sampling distribution variances larger. It is sometimes surprising to see the degree to which otherwise very proficient modelling professionals are unaware, unconcerned or lacking in resources to address identification issues. Modellers should invest some effort in analysing and characterising how the dependent response behaviour variables were created. Sometimes it is worth building separate models corresponding to specific dependent variable creation processes just to see how much difference it makes. The relatively higher variances associated with difference calculations between two models' predictions, discussed at the end of the problem formulation section, make it more important to pay attention to and discipline the dependent variable creation process.

\section{Developing independent variables}

When models are expected to predict response by channel it is imperative that the set of independent predictor variables be reviewed. Some predictive variables may have more or less the same relationship to predicting response, regardless of channel. It is, however, surprisingly hard to think of typically powerful predictor variables that are not likely to have some relationship to channel preference. Many variables will have very different impacts on each channel model, but the representation of the variable used in the modelling process would be the same in each case; likely examples of this situation would be age and gender variables.

The main issue that needs attention is that prior channel usage is likely to be predictive of future usage by channel. Tables 3 and 4 illustrated the type of consistent preference for one channel that is commonly seen. The implication for independent variable development is that variables which summarise prior purchasing activity need to be disaggregated by channel. So, for example, rather than build overall recency, frequency and 


\section{Incremental profit calculations}

\section{Decisions should consider all channels}

monetary variables, the modeller would build offline recency, frequency and monetary variables and a parallel set of online purchase history variables. When a channel, such as the internet, is relatively new it is important for the modeller to monitor changes in the descriptive statistics relating to its activity. Since the underlying variable statistics are likely to change as the channel matures, it is likely that model parameters will need to be re-estimated more frequently than they would for a more stable business situation.

\section{Marketing management and targeting issues}

For the marketing manager the issues discussed above should be of interest because they can have direct implications for name selection and targeting. As an example, consider a simple and lucky situation with a potential mailing that has the expected demand by segment illustrated previously in Table 2. Only a single response model is used. Suppose that the relevant financial data are:

- mailing pieces cost $\$ 0.60$ each

- the product has 45 per cent margin

- the average order size is $\$ 80$

- the average processing cost per order is $\$ 10$.

The profit formula would be:

Profit $=0.45 \times$ incremental demand $-0.60-\$ 10 \times($ incremental demand/average order $)$

The expected profit from offline, online and total incremental demand is shown in Table 5.

The notable point illustrated by Table 5 is that if only offline demand is considered, a profit-maximising marketer will select only deciles 1,2 and 3 for the mailing. When total demand is considered, however, deciles 1, 2, 3 and 4 will be selected. It should be expected that including all channels'

Table 5: Per customer incremental demand and profit

\begin{tabular}{|c|c|c|c|c|c|c|}
\hline \multirow[t]{2}{*}{ Decile } & \multicolumn{2}{|c|}{ Offline } & \multicolumn{2}{|c|}{ Online } & \multicolumn{2}{|c|}{ Total } \\
\hline & $\begin{array}{l}\text { Increment demand } \\
(\$)\end{array}$ & $\begin{array}{l}\text { Profit* } \\
\text { (\$) }\end{array}$ & $\begin{array}{l}\text { Increment demand } \\
(\$)\end{array}$ & $\begin{array}{l}\text { Profit* } \\
\text { (\$) }\end{array}$ & $\begin{array}{l}\text { Increment demand } \\
\text { (\$) }\end{array}$ & $\begin{array}{l}\text { Profit } \\
(\$)\end{array}$ \\
\hline 1 & 7.69 & 1.90 & 2.12 & 0.69 & 9.81 & 2.59 \\
\hline 2 & 3.22 & 0.45 & 1.03 & 0.33 & 4.25 & 0.78 \\
\hline 3 & 2.18 & 0.11 & 0.65 & 0.21 & 2.83 & 0.32 \\
\hline 4 & 1.53 & $(0.10)$ & 0.44 & 0.14 & 1.97 & 0.04 \\
\hline 5 & 1.18 & $(0.22)$ & 0.34 & 0.11 & 1.52 & $(0.11)$ \\
\hline 6 & 0.94 & $(0.29)$ & 0.29 & 0.09 & 1.23 & $(0.20)$ \\
\hline 7 & 0.75 & $(0.36)$ & 0.24 & 0.08 & 0.99 & $(0.28)$ \\
\hline 8 & 0.69 & $(0.38)$ & 0.22 & 0.08 & 0.91 & $(0.30)$ \\
\hline 9 & 0.57 & $(0.41)$ & 0.19 & 0.06 & 0.76 & $(0.35)$ \\
\hline 10 & 0.53 & $(0.43)$ & 0.19 & 0.06 & 0.72 & $(0.37)$ \\
\hline
\end{tabular}

* All of the mailing cost (\$0.60 per piece) is allocated against the offline profit calculation in order to show clearly the effect of not considering incremental online demand. This cost allocation decision makes no difference when total incremental demand is used for decision making. 
incremental demand will tend to raise the quantity of names that are expected to be profitable.

To make the illustration more realistic, consider a simple change to the cost structure:

— the average processing cost per offline order is $\$ 12.50$

— the average processing cost per online order is $\$ 6.50$.

Typically the cost of taking an order, handling status enquiries and sending notifications is much lower for online processing. In this situation the customer's channel preference is quite relevant to the selection and targeting decisions. Applying the profit formula by channel to the data from Tables 3 and 4 (adjusted to consider only incremental demand) gives the expected profit shown in Table 6.

Profit maximisation leads the marketer to select deciles $1-5$ for

\section{Decision process} customers with over 25 per cent of their prior purchasing from the internet (minus, perhaps, those with 75-99 per cent prior internet purchasing). Offline-only customers are selected only from deciles 1, 2 and 3.

All the preceding discussion and examples pertain to making marketing decisions with a single model. When multiple, channel-specific models are used the procedure that should be followed is as detailed below.

- Score each customer on each model to produce response demand estimates.

- Calculate incremental demand estimates for each channel by starting with 'contact' demand estimates and subtracting 'no-contact' estimates.

- Apply the financial information about product, processing and marketing costs to produce a profit estimate for each customer.

- The selection process depends on the business environment. If the business wants to make all profitable contacts, then select all names with an expected profit greater than zero. If the business has a fixed,

Table 6: Per customer expected profit by decile and prior channel usage

\begin{tabular}{|ccccccc|}
\hline Decile & \multicolumn{5}{c|}{ Prior purchasing percentage by channel } \\
\cline { 2 - 7 } & $\begin{array}{c}\text { Only offline } \\
\mathbf{( \$ )}\end{array}$ & $\begin{array}{c}\text { Internet 1-24\% } \\
\mathbf{( \$ )}\end{array}$ & $\begin{array}{c}\text { Internet 25-49\% } \\
\mathbf{( \$ )}\end{array}$ & $\begin{array}{c}\text { Internet 50-74\% } \\
\mathbf{( \$ )}\end{array}$ & $\begin{array}{c}\text { Internet 75-99\% } \\
\mathbf{( \$ )}\end{array}$ & $\begin{array}{c}\text { Only internet } \\
\mathbf{( \$ )}\end{array}$ \\
\hline 1 & 2.28 & 2.47 & 2.54 & 2.70 & 2.96 & 2.95 \\
2 & 0.63 & 0.72 & 0.87 & 0.97 & 1.12 & 1.29 \\
3 & 0.22 & 0.29 & 0.39 & 0.61 & 0.42 & 0.62 \\
4 & $(0.03)$ & 0.11 & 0.13 & 0.03 & 0.17 & 0.16 \\
5 & $(0.18)$ & $(0.03)$ & $(0.00)$ & 0.02 & $(0.01)$ & 0.00 \\
6 & $(0.26)$ & $(0.11)$ & $(0.11)$ & $(0.12)$ & $(0.11)$ & $(0.11)$ \\
7 & $(0.33)$ & $(0.18)$ & $(0.16)$ & $(0.14)$ & $(0.14)$ & $(0.18)$ \\
8 & $(0.35)$ & $(0.21)$ & $(0.19)$ & $(0.18)$ & $(0.18)$ & $(0.22)$ \\
9 & $(0.40)$ & $(0.22)$ & $(0.24)$ & $(0.23)$ & $(0.22)$ & $(0.26)$ \\
10 & $(0.41)$ & $(0.24)$ & $(0.25)$ & $(0.24)$ & $(0.23)$ & $(0.27)$ \\
\hline
\end{tabular}




\section{Consider multiple contact alternatives}

budgeted quantity of names to contact, then the customers should be sorted on the basis of their estimated profit. Selection then consists of working with the sorted list of names to pick the best names to meet the budgeted quantity.

While the above process will yield an efficient tactical selection for a particular targeted contact, there are broader and more strategic issues that may be considered.

There may be multiple alternative ways to contact each customer. In particular, instead of an offline communication the marketer is likely to have the option of an internet communication instead. In fact, for the cost of one mail piece the marketer is likely to be able to substitute many e-mails. The point here is that showing a marketing contact will be profitable does not necessarily mean it is optimal when compared to other alternatives. Moreover, the profitability of multiple marketing contacts addressed to the same customer is very rarely linearly additive; most commonly there are sharply diminishing incremental profitability returns to more intense marketing. Selecting optimal multi-contact marketing strategies among multiple alternatives is a complex subject unto itself.

Many businesses have strategic objectives that include pushing the development of a particular channel. In recent years companies focused on developing their internet businesses because of the low marginal cost of internet communications, low order-processing costs and, of course, because it was the wave of the future. The high fixed costs of website development make it very important for companies to achieve economies of scale by building up their business volume in this channel. The tactical profit calculations may be integrated with strategic policies to try to direct a business' growth track.

\section{Generalisations}

The discussion and examples have focused on a business with an offline communication that will stimulate incremental business in one offline and one online channel. The principles discussed generalise in several ways, however.

- Any type of targeted communication should be considered in the manner described above. Internet communications should be evaluated in terms of their stimulation of both offline and online incremental demand.

- What was most important about the internet channel in the discussion above was that it had lots of demand whether or not the customer received a targeted communication. The difficult modelling issue illustrated was prediction of each customer's incremental expected response. Many modellers have encountered this issue previously when trying to model incremental retail store sales stimulated by targeted communications. The same issues often exist for manufacturers which sell through dealer networks. With retail and dealer channels the modelling problem may be more difficult because the percentage of sales that can be identified by customer and 


\section{Multiple channels make modelling more complex}

attributed to a marketing communication is typically much lower than it is for internet shopping.

- When a marketing communication stimulates response in more than two channels, the approach recommended above extends in fairly simple ways. Tables 2 and 5 could have more columns which would show effects in the additional channels. There are more calculations to get total incremental effects, but the conceptual complexity does not rise at all.

When multiple marketing communications are interacting, accurate modelling becomes much more difficult. Modellers often build inaccurate models of response to a particular marketing contact because the effects of other largely concurrent contacts are not taken into account. This inaccurate modelling problem occurs whenever there are no predictor variables representing other contacts in the same time period as the marketing contact being modelled. It is a particularly important matter when there is high variability in other contacts among the customer population. A common form of the problem occurs when only certain customer segments receive prior or subsequent marketing contacts that cannibalise some of the response that would otherwise be triggered by the modelled marketing contact. The more there are multiple communications media, the larger the impact of this methodology issue; the development of internet marketing, therefore, should alert modellers' attention to the issue.

\section{Summary}

For most organisations the marketing realities of the 21 st century include both stimulating demand through multiple media and capturing demand through multiple channels. To be maximally useful the predictive modelling practices need to adapt to that reality and give marketers strong tools with which to manage their expenditures. Therefore, several key ideas should be incorporated into the response modelling process.

- Model all relevant channel responses that are stimulated by marketing, but be thoughtful about associating responses to a particular stimulation.

- Proceed with caution in adding complexity to the modelling and scoring processes. Economically optimal solutions do not push modelling technology unnecessarily.

- Incremental response predictions are the foundation for marketing planning, but comparing (subtracting) model predictions significantly expands the overall associated variance.

- Variable creation needs focused analytical attention. Dependent variable creation will often reflect processing system characteristics, and thereby introduce unwanted biases. Independent variables need to be created that reflect prior customer channel preferences.

The increased complexity in the commercial environment will increase 
the relative importance of modelling technology, if it is applied appropriately. Modellers should welcome the opportunity.

\section{References}

1. David Shepard Associates (1999) The New Direct Marketing, McGraw Hill, Boston, MA.

2. Drozdenko, R. G. and Drake, P. D. (2002) Optimal Database Marketing, Sage Publications, Thousand Oaks, CA.

3. Hansotia, B. and Rukstales, B. (2002) 'Incremental value modelling', Journal of Interactive Marketing, Vol. 16, No. 3, pp. 35-46.

4. Malthouse, E. C. (2001) 'Assessing the performance of direct marketing scoring models', Journal of Interactive Marketing, Vol. 15, No. 1, pp. 49-62. 